\title{
Nonsteroidal Anti-Inflammatory Drug Use Among Persons With Chronic Kidney Disease in the United States
}

\author{
Laura Plantinga, ScM ${ }^{1,2}$ \\ Vanessa Grubbs, $M D^{1}$ \\ Urmimala Sarkar, $M D^{1,2}$ \\ Chi-yuan Hsu, MD \\ Elizabeth Hedgeman, MS \\ Bruce Robinson, $M D^{4}$ \\ Rajiv Saran, $M D^{3}$ \\ Linda Geiss, $\mathrm{MS}^{5}$ \\ Nilka Ríos Burrows, MPH \\ Mark Eberhardt, $P b D^{6}$ \\ Neil Powe, $M D^{1,2}$

\section{For the CDC CKD Surveillance} \\ Team
}

'Department of Medicine, University of California, San Francisco, California

${ }^{2}$ Center for Vulnerable Populations, San Francisco General Hospital, San Francisco, California

${ }^{3}$ Department of Medicine, University of Michigan, Ann Arbor, Michigan

${ }^{4}$ Arbor Research Collaborative for Health, Ann Arbor, Michigan

${ }^{5}$ Division of Diabetes Translation, Centers for Disease Control and Prevention, Atlanta, Georgia

${ }^{6}$ National Center for Health Statistics, Hyattsville, Maryland

Conflicts of interest: $B$. Robinson received grants in the last 3 years from Abbott Laboratories, Amgen, Genzyme Corporation, and Kyowa Hakko Kirin, all other authors report none.

\section{CORRESPONDING AUTHOR}

Laura Plantinga, ScM

Department of Epidemiology

Rollins School of Public Health

Claudia Nance Rollins Building, 3rd Floor

1518 Clifton Rd NE

Atlanta, GA 30322

laura.plantinga@emory.edu

\begin{abstract}
PURPOSE Because avoidance of nonsteroidal anti-inflammatory drugs (NSAIDs) is recommended for most individuals with chronic kidney disease (CKD), we sought to characterize patterns of NSAID use among persons with CKD in the United States.

METHODS A total of 12,065 adult (aged 20 years or older) participants in the cross-sectional National Health and Nutrition Examination Survey (1999-2004) responded to a questionnaire regarding their use of over-the-counter and prescription NSAIDs. NSAIDs (excluding aspirin and acetaminophen) were defined by self-report. CKD was categorized as no CKD, mild CKD (stages 1 and 2; urinary albumin-creatinine ratio of $\geq 30 \mathrm{mg} / \mathrm{g}$ ) and moderate to severe CKD (stages 3 and 4; estimated glomerular filtration rate of $15-59 \mathrm{~mL} / \mathrm{min} / 1.73 \mathrm{~m}^{2}$ ). Adjusted prevalence was calculated using multivariable logistic regression with appropriate population-based weighting.
\end{abstract}

RESULTS Current use (nearly every day for 30 days or longer) of any NSAID was reported by $2.5 \%, 2.5 \%$, and $5.0 \%$ of the US population with no, mild, and moderate to severe CKD, respectively; nearly all of the NSAIDs used were available over-the-counter. Among those with moderate to severe CKD who were currently using NSAIDs, $10.2 \%$ had a current NSAID prescription and $66.1 \%$ had used NSAIDs for 1 year or longer. Among those with CKD, disease awareness was not associated with reduced current NSAID use: $(3.8 \%$ vs $3.9 \%$, aware vs unaware; $P=.979$ ).

CONCLUSIONS Physicians and other health care clinicians should be aware of use of NSAIDs among those with CKD in the United States and evaluate NSAID use in their CKD patients.

Ann Fam Med 2011;9:423-430. doi:10.1370/afm.1302.

\section{INTRODUCTION}

$\mathrm{B}$ oth over-the-counter and prescription nonsteroidal anti-inflammatory drugs (NSAIDs) are widely used in the United States. ${ }^{1}$ General medicine textbooks ${ }^{2-4}$ and nephrology subspecialty consensus guidelines (National Kidney Foundation) ${ }^{5}$ recommend avoidance of NSAIDs (except aspirin and acetaminophen) for most patients with chronic kidney disease (CKD). Persons with CKD, however, are likely unaware of their disease $^{6}$ and may also be unaware that NSAIDs should be avoided. Additionally, those with CKD are likely to be older and have multiple comorbid conditions or symptoms that lead to increased use of NSAIDs. ${ }^{7}$

NSAIDs have been associated both with acute kidney injury in the general population ${ }^{8}$ and with disease progression in those with CKD. ${ }^{9}$ For those with CKD, the further decrease in volume of renal blood flow resulting from decreased prostaglandin synthesis can lead to acute kidney injury, sodium retention, edema, hypertension, and hyperkalemia. ${ }^{10}$ Acute interstitial nephritis can cause kidney damage and reduced renal func- 
tion in a small percentage of NSAID users. ${ }^{11}$ Habitual NSAID abuse can lead to analgesic nephropathy, a condition that is often irreversible upon drug discontinuation. ${ }^{12}$ Additionally, NSAIDs interact unfavorably with some commonly prescribed medications, including loop diuretics, angiotensin-converting enzyme inhibitors, and angiotensin receptor blockers, leading to reduced effectiveness, along with increased risk of renal impairment. ${ }^{13,14}$ Although epidemiologic studies have linked NSAID use to progressive CKD, ${ }^{15}$ the risks of NSAIDs in patients with CKD, while supported by consensus and theoretical effect, remain less clearly established by evidence.

Despite the potential adverse renal effects of NSAIDs, little is known about the patterns of NSAID use among those with CKD in community settings. Here we estimate the prevalence and describe patterns of self-reported NSAID use among adults by CKD status using data from the community-based National Health and Nutrition Examination Survey (NHANES).

\section{METHODS}

\section{Study Design}

We conducted a cross-sectional study of participants from NHANES, which consists of standardized in-home interviews and physical examinations and specimen collections at mobile examination centers of representative samples of noninstitutionalized US civilian residents. ${ }^{16}$ A complex, multistage, probability sampling design was used, with oversampling of certain subpopulations to increase reliability of estimates. Response rates for participants completing both the interview and examination were 76\% (1999-2000), $80 \%(2001-2002)$, and $76 \%(2003-2004)$, for a total of 14,213 participants.

There were 12,065 NHANES 1999-2004 participants ( $\mathrm{n}=3,753,4,297$, and 4,015 for 1999-2000, 2001 2002, and 2003-2004, respectively) who were aged 20 years or older, responded to the analgesic questionnaire, and had available serum creatinine and urine albumin and creatinine measurements; exclusions were pregnancy and estimated glomerular filtration rate (eGFR) of less than $15 \mathrm{~mL} / \mathrm{min} / 1.73 \mathrm{~m}^{2}$ (Figure 1). All participants gave written informed consent. The protocol was approved by the National Center for Health Statistics Research Ethics Review Board.

\section{Measurements}

During the interview, participants reported on current and past use of specific over-the-counter and prescription analgesic pain relievers via a computer-assisted personal interviewing system. Additionally, partici- pants were asked to provide bottles of all prescription medications taken within the past month for recording by interviewers. Self-reported information on demographics (age, sex, and race/ethnicity), socioeconomic status and health care access (education and income), and diagnosed diseases and conditions was also obtained during the interview.

Height, weight, and blood pressure were measured, and samples were collected during the examination. Serum creatinine was measured by the modified kinetic method of Jaffe and corrected for different analyzers as specified in NHANES documentation. ${ }^{17,18}$ Urine albumin and creatinine were measured using solidphase fluorescence immunoassay and the modified Jaffe kinetic method, respectively.

\section{Definitions \\ CKD}

Patients' CKD status was defined by single measurements of kidney function (estimated glomerular filtration rate $[\mathrm{eGFR}]$ ) and albuminuria (albumin:creatinine ratio $[\mathrm{ACR}]$ ), as follows: no CKD, eGFR $\geq 60 \mathrm{~mL} /$ $\mathrm{min} / 1.73 \mathrm{~m}^{2}$, and $\mathrm{ACR} \leq 30 \mathrm{mg} / \mathrm{g}$; stages 1 and 2 (mild CKD), eGFR $\geq 60 \mathrm{~mL} / \mathrm{min} / 1.73 \mathrm{~m}^{2}$, and $A C R \geq 30$ $\mathrm{mg} / \mathrm{g}_{\text {; }}$ and stages 3 and 4 (moderate to severe CKD),

\section{Figure 1. Flowchart of cumulative study participant exclusions.}

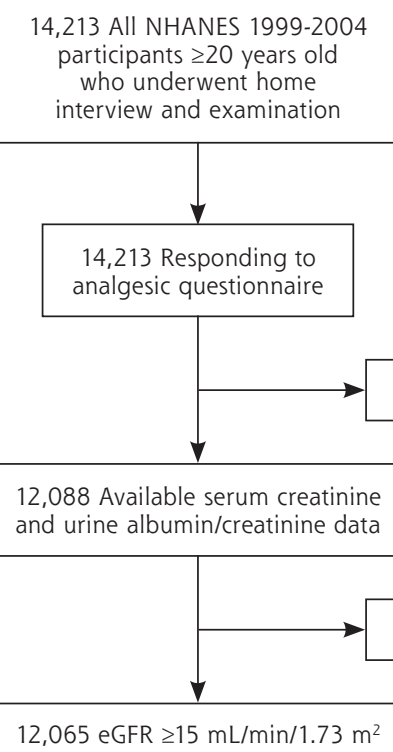

12,088 Available serum creatinine and urine albumin/creatinine data

12,065 eGFR $\geq 15 \mathrm{~mL} / \mathrm{min} / 1.73 \mathrm{~m}^{2}$

eGFR $=$ estimated glomerular filtration rate; NHANES $=$ National Health and Nutrition Examination Survey. 
Figure 2. Questionnaire items and study definitions for reported over-the-counter and prescription NSAID use, National Health and Nutrition Examination Survey, 1999-2004.

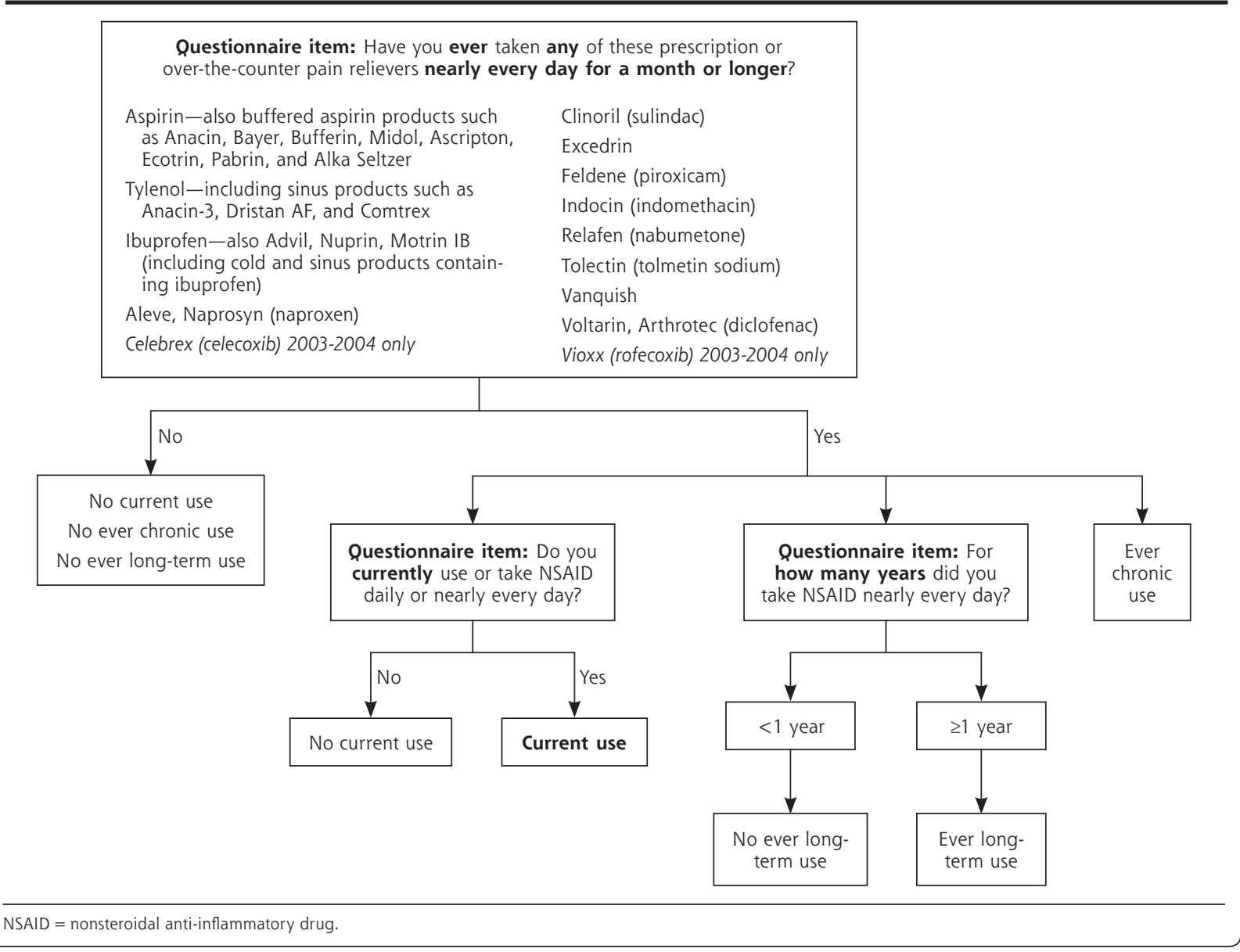

eGFR $15-59 \mathrm{~mL} / \mathrm{min} / 1.73 \mathrm{~m}^{2}$. eGFR was calculated according to the modified Modification of Diet in Renal Disease (MDRD) Study equation for calibrated creatinine was $\mathrm{eGFR}=175 \times[$ (calibrated serum creatinine in $\left.\mathrm{mg} / \mathrm{dL})^{-1.154}\right] \times$ age $\mathrm{e}^{-0.203} \times(0.742$ if female $) \times$ (1.210 if African-American). ${ }^{19}$

\section{NSAID Use}

Current use of NSAIDs was defined by self-reported use of ibuprofen, naproxen, sulindac, piroxicam, indomethacin, tolmetin, or diclofenac (with brand names and combination formulas identified) daily or nearly every day for the last 30 days (Figure 2). Number of pills or doses per day were also collected on those reporting current use. Long-term use was defined by use for 1 year or longer (Figure 2). Current NSAID prescriptions were identified in the prescription medication database. Although the questionnaire assessed the use of aspirin and acetaminophen, these medications were excluded from our primary definitions of NSAID use because of their relatively low nephrotoxic- ity and recommended use for pain (acetaminophen) or for the prevention of comorbid cardiovascular disease (aspirin) in the setting of known CKD. ${ }^{20}$

\section{Covariates}

Comorbid diseases were defined by self-reported diagnosis. Self-reported cardiovascular disease was defined by diagnosed coronary artery disease, angina, myocardial infarction, stroke, or congestive heart failure. Hypertension was defined by self-report, self-reported use of anti-hypertensive medications, or by measured systolic or diastolic blood pressure of $\geq 140$ or $\geq 90 \mathrm{~mm}$ $\mathrm{Hg}$, respectively. Obesity was defined by a measured body mass index (BMI) of $\geq 30 \mathrm{~kg} / \mathrm{m}^{2}$. CKD awareness was defined as a yes answer to "Have you ever been told by a doctor or other health professional that you have weak or failing kidneys?" Angiotensin-converting enzyme inhibitors and angiotensin receptor blockers included captopril, enalapril, fosinopril, lisinopril, candesartan, eprosartan, irbesartan, losartan, olmesartan, telmisartan, and valsartan; loop diuretics included furo- 
semide, torsemide, and bumetanide (prescriptions for ethacrynic acid were not reported).

\section{Statistical Methods}

Unweighted characteristics of patients were calculated and compared by CKD status. Unadjusted and adjusted weighted prevalence estimates of current NSAID use were calculated by CKD category, and variance of proportions was estimated with Taylor series linearization. Sensitivity analyses with definition of reduced kidney function by the CKD-EPI equation, ${ }^{21}$ with further adjustment for additional covariates, and with stratification by arthritis were performed. All weighted analyses were performed using the SVY commands in Stata 10.0 (College Station, Texas) to account for study design weights, strata, and primary sampling units. Statistical significance was set at $P<.05$.

\section{RESULTS}

\section{Participant Characteristics}

The NHANES participants with CKD were older, more likely to be female and non-Hispanic black, and more likely to have lower income and educational attainment than their counterparts without CKD (Table 1). With US population-based weighting, trends were similar to those seen in the unweighted results in Table 1, except that the non-Hispanic black and white populations were similarly likely to have CKD (data not shown).

\section{Prevalence of Reported NSAID Use by Patients With CKD}

\section{Reported Current NSAID Use}

Reported current use of NSAIDs was not uncommon in the US population (3.7\% overall). Persons with moderate to severe CKD were slightly more likely than those with no or mild CKD to report current use of NSAIDs (Figure 3A). The great majority of currently used NSAIDs were available over-the-counter (Figure 3A). Among those with CKD, current NSAID use was similar among those were aware and those who were unaware of their CKD status $(5.7 \%$ vs $5.0 \%, P=.80)$.

More than two-thirds (65.7\%) of current NSAIDs users also reported long-term use of NSAIDs (1 year or longer), and the prevalence of ever reporting long-term use did not differ by current CKD status (Figure 3B). The mean number of pills or doses per day among current NSAID users was 3.0, 3.3, and 2.6 for no, mild, and moderate to severe CKD, respectively $(P=.34)$.

\section{Current NSAID Prescriptions}

Of those reporting current NSAID use, $19.4 \%$ also had a current prescription for a NSAID, with higher prevalence among those with no CKD (21.8\%) vs mild (10.7\%) or moderate to severe (9.8\%) CKD (Figure 3B). Regardless of self-reported current NSAID use, $11.4 \%$ of those with moderate to severe CKD reported a NSAID prescription compared with $7.6 \%$ for mild CKD $(P=.007)$.

\section{Other Current Prescriptions}

Angiotensin-converting enzyme inhibitors and angiotensin receptor blockers were reported for $9.3 \%$ of current NSAID users (19.4\% and $19.1 \%$ for mild and moderate to severe CKD, respectively). In addition, 3.7\% of current NSAIDs users had prescriptions for loop diuretics (17.8\% for moderate to severe CKD). Among participants with CKD stage 3 or 4 who reported prescriptions for NSAIDs, $15.7 \%$ and $20.4 \%$ also had prescriptions for angiotensin-converting enzyme inhibitors, angiotensin receptor blockers, and loop diuretics.

\section{Sensitivity Analyses}

The distribution of reported current NSAID use by CKD defined by the CKD-EPI equation ${ }^{21}$ did not differ substantially from those who reported using the MDRD Study equation (data not shown). Adjustment for demographics and clinical conditions did not substantially change the results (data not shown). Stratified analyses showed that, although current NSAID use was substantially higher among those with arthritis, the association of greater prevalence of NSAID use among those with CKD stage 3 or 4 , relative to those with earlier stage or no CKD, did not differ by arthritis status (no arthritis: $2.5 \%, 2.8 \%$, and $3.4 \%$ NSAID use for no CKD, CKD stage 1 and 2, and CKD stage 3 and 4, respectively; arthritis, $7.6 \%, 7.7 \%$, and $8.1 \%$ NSAID use, $P_{\text {interaction }}=.85$ and .47 for CKD stage 1 or 2 and stage 3 or 4 , respectively).

\section{DISCUSSION}

We found that current use of NSAIDs, particularly those available over-the-counter, was low but not rare in the US population with CKD, with more than $5 \%$ of those with moderate to severe CKD reporting currently using NSAIDs regularly. At a population level, this percentage reflects up to 870,000 persons in the United States with advanced CKD who are using NSAIDs. The prevalence of current NSAID use in the general population did not differ substantially by CKD status, and two-thirds of all current users had used NSAIDs for at least 1 year. Current prescriptions for NSAIDs were also common overall and in those with CKD ( 10\%), possibly reflecting the lack of both clinician awareness of CKD status and possible adverse effects of NSAIDs in patients with CKD who have additional competing indications for NSAID use (eg, chronic pain). Many of those with CKD who had pre- 
Table 1. Characteristics of Study Participants, by Chronic Kidney Disease Status, National Health and Nutrition Examination Survey, 1999-2004

\begin{tabular}{|c|c|c|c|c|}
\hline \multirow[b]{2}{*}{ Characteristic } & \multirow[b]{2}{*}{ Overall } & \multicolumn{3}{|c|}{ CKD Status $^{a}$} \\
\hline & & No $C^{\prime} D^{b}$ & Mild CKDc & Moderate-Severe CKD \\
\hline No. (\%) participants & $12,065(100)$ & $9,604(79.6)$ & $1,137(9.4)$ & $1,324(11.0)$ \\
\hline \multicolumn{5}{|l|}{ Sociodemographic } \\
\hline Age, mean (SD) y & $51.0(18.7)$ & $47.2(17.2)$ & $57.5(18.0)$ & $72.9(11.8)$ \\
\hline \multicolumn{5}{|l|}{ Sex, \% } \\
\hline Male & 51.6 & 53.4 & 46.6 & 48.7 \\
\hline Female & 48.4 & 46.6 & 53.4 & 51.3 \\
\hline \multicolumn{5}{|l|}{ Race/ethnicity, \%e } \\
\hline Non-Hispanic white & 40.1 & 41.3 & 37.6 & 37.7 \\
\hline Non-Hispanic black & 24.8 & 23.5 & 24.6 & 28.2 \\
\hline Mexican-American & 25.5 & 25.7 & 27.1 & 24.7 \\
\hline \multicolumn{5}{|l|}{ Household Income, \% } \\
\hline$<\$ 20,000$ & 25.7 & 23.7 & 31.1 & 29.3 \\
\hline$\$ 20,000-44,999$ & 32.9 & 32.6 & 33.6 & 33.5 \\
\hline$\$ 45,000-74,999$ & 20.6 & 21.3 & 19.1 & 19.3 \\
\hline$>\$ 75,000$ & 20.8 & 22.4 & 16.2 & 18.0 \\
\hline \multicolumn{5}{|l|}{ Education, \% } \\
\hline Less than high school & 49.5 & 43.0 & 53.0 & 68.3 \\
\hline High school graduate & 50.5 & 57.0 & 47.1 & 31.7 \\
\hline \multicolumn{5}{|l|}{ Clinical } \\
\hline \multicolumn{5}{|l|}{$\mathrm{BMI} \geq 30 \mathrm{~kg} / \mathrm{m}^{2}, \%$} \\
\hline No & 75.8 & 73.0 & 69.1 & 85.3 \\
\hline Yes & 24.2 & 27.0 & 30.9 & 14.7 \\
\hline \multicolumn{5}{|l|}{ Diabetes (self-reported), \% } \\
\hline No & 93.2 & 95.0 & 80.6 & 92.7 \\
\hline Yes & 6.8 & 5.0 & 19.5 & 7.4 \\
\hline \multicolumn{5}{|c|}{$\begin{array}{l}\text { Hypertension (self-reported, use of medications, } \\
\text { or } \geq 140 / 90 \mathrm{~mm} \mathrm{Hg} \text { ), \% }\end{array}$} \\
\hline No & 50.3 & 60.9 & 37.1 & 19.4 \\
\hline Yes & 49.7 & 39.1 & 62.9 & 80.6 \\
\hline \multicolumn{5}{|c|}{ Cardiovascular disease (self-reported), \% } \\
\hline No & 88.1 & 92.3 & 82.2 & 71.5 \\
\hline Yes & 11.9 & 7.7 & 17.8 & 28.5 \\
\hline \multicolumn{5}{|l|}{ Cancer (self-reported), \% } \\
\hline No & 90.8 & 92.8 & 89.8 & 81.4 \\
\hline Yes & 9.3 & 7.2 & 10.2 & 18.7 \\
\hline \multicolumn{5}{|l|}{ Arthritis (self-reported), \% } \\
\hline No & 72.4 & 76.6 & 65.0 & 56.2 \\
\hline Yes & 27.6 & 23.4 & 35.0 & 43.8 \\
\hline \multicolumn{5}{|c|}{ Last visit to health care clinician, $\%$} \\
\hline$>1$ y ago & 17.0 & 18.9 & 14.0 & 13.3 \\
\hline Within last year & 83.0 & 81.1 & 86.0 & 86.8 \\
\hline \multicolumn{5}{|c|}{ ACEI or ARB prescription, $\%$} \\
\hline No & 95.5 & 96.1 & 92.1 & 95.0 \\
\hline Yes & 4.5 & 3.9 & 7.9 & 5.0 \\
\hline \multicolumn{5}{|c|}{ Loop diuretic prescription, \% } \\
\hline No & 97.7 & 98.9 & 95.8 & 95.3 \\
\hline Yes & 2.3 & 1.1 & 4.2 & 4.7 \\
\hline \multicolumn{5}{|l|}{ CKD awareness, \% } \\
\hline No & 92.5 & & 95.6 & 89.8 \\
\hline Yes & 7.5 & & 4.4 & 10.2 \\
\hline \multicolumn{5}{|c|}{$\begin{array}{l}\text { ACR = albumin-creatinine ratio; } A C E I=\text { angiotensin-converting enzyme inhibitor; } A R B=\text { angiotensin receptor blocker; } B M I=\text { body mass index; } C K D=\text { chronic kidney } \\
\text { disease; } \mathrm{eGFR}=\text { estimated glomerular filtration rate. }\end{array}$} \\
\hline Note: Estimates are unweigh & Ilation) estimates. & & & \\
\hline $\begin{array}{l}\text { a } P<.001 \text { for all comparison } \\
\text { b ACR } \leq 30 \mathrm{mg} / \mathrm{g}, \text { eGFR } \geq 60 \\
\text { ' Stages } 1 \mathrm{and} 2 \text { (ACR } \geq 30 \mathrm{~m} \\
\text { d Stages } 3 \text { and } 4 \text { (eGFR } 15-55 \\
\text { e Other race excluded from a }\end{array}$ & variance (continuou & les) and $\chi^{2}$ (categor & variables). & \\
\hline
\end{tabular}


scriptions for NSAIDs also had prescriptions for angiotensin-converting enzyme inhibitors and angiotensin receptor blockers $(\sim 16 \%)$ and loop diuretics $(\sim 20 \%)$, the therapeutic action of which is inhibited by NSAIDs. ${ }^{10}$ Not surprisingly, NSAID use was greater among those who had arthritis compared with those who did not.

\section{Informed Decision Making Regarding NSAID Use in the Setting of CKD}

Our findings suggest that there may be large numbers of individuals with CKD, many of whom unaware of their disease, ${ }^{6}$ who may be at risk for further kidney injury through use of NSAIDs. Awareness not only of CKD status but also of Figures $3 \mathrm{~A}$ and B. Crude reported use of nonsteroidal anti-inflammatory drugs in the US population by chronic kidney disease status, National Health and Nutrition Examination Survey, 1999-2004.

A. Reported current use (nearly every day for the last 30 or more days), by type of NSAID.

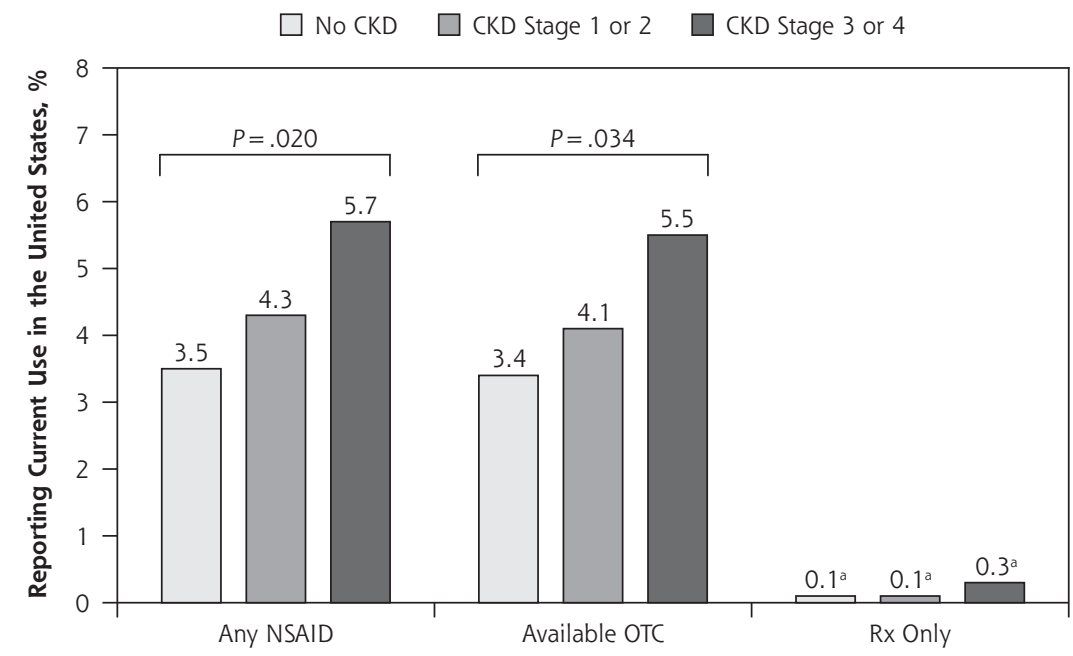

B. Reported long-term use (1 year or longer) and current NSAID prescriptions, among those reporting current use of any NSAID.

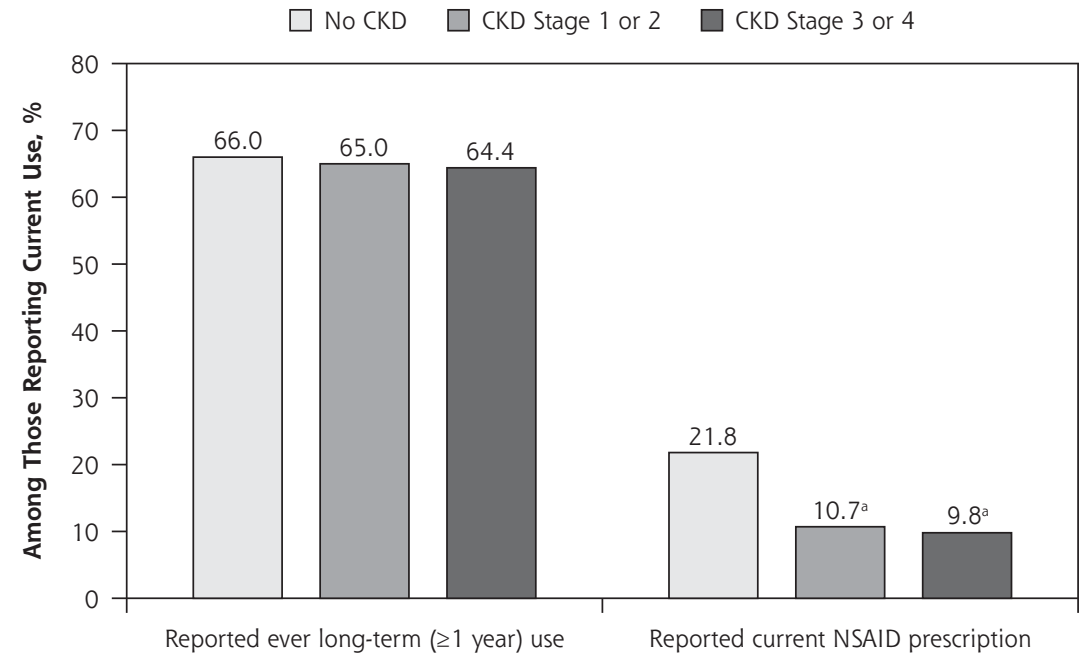

$\mathrm{CKD}=$ chronic kidney disease; NSAID = nonsteroidal anti-inflammatory drug; OTC = over-the-counter; $\mathrm{Rx}=$ prescription.

Note: $P>.05$ across CKD categories by $\chi^{2}$, except where indicated. OTC drugs included ibuprofen and naproxen; Rx-only drugs included sulindac, piroxicam, indomethacin, tolmetin, diclofenac, celecoxib, and rofecoxib. Prescription NSAIDs included ibuprofen, naproxen, sulindac, piroxicam, indomethacin, tolmetin, diclofenac, nimesulide, meclofenamate, etodolac, ketorolac, flurbiprofen, and ketoprofen.

a Unreliable estimates because of small sample sizes. necessary behavioral modifications, including recommended NSAID avoidance or restriction, is important to avoid CKD progression. We found no evidence that those who were aware of their CKD were less likely to use NSAIDs over the long term than were those who were unaware, suggesting that awareness of recommended NSAID avoidance in CKD is not associated with awareness of CKD itself. We also found that many of those with prescriptions for NSAIDs had prescriptions for angiotensin-converting enzyme inhibitors and angiotensin receptor blockers or loop diuretics as well. The nephrotoxicity of and potential interactions with these drugs may need to be more clearly communicated to primary care clinicians, other prescribers of medications for pain management, and the community. This communication is important to those individuals who self-manage pain with over-the-counter NSAIDs, given that explicit labeling regarding the potential renal risks of the overthe-counter ibuprofen and naproxen, as has been recommended ${ }_{1}^{20}$ is not required.

It is important to note that, although there is general consensus that NSAIDs should be avoided in CKD, the evidence supporting this belief remains mixed. In the 1990s, casecontrol studies ${ }^{22,23}$ indicated that the risk of progression to end-stage renal disease was increased in those who took 
NSAIDs. Cohort studies have shown that up to $13 \%$ to $18 \%$ of elderly and hospitalized patients ${ }^{24,25}$ develop acute renal failure in response to NSAIDs, and elderly high-dose NSAID users had a $26 \%$ increased risk of progression. ${ }^{9}$ More recent cohort studies show that long-term NSAID use may have either no ${ }^{26,27}$ or moderate $^{28}$ effect on the renal function of healthy men and women. The concept of classic analgesic nephropathy ${ }^{29}$ has now been largely attributed to abuse of phenacetin-containing analgesic mixtures ${ }^{30}$ which are no longer available in the United States, Australia, and most of Western Europe but continue to be associated with $\mathrm{CKD}$ and end-stage renal disease in countries where such mixtures are available. ${ }^{31}$

This contradictory body of evidence may be one contributing factor to the continuing use of NSAIDs among persons with CKD. Common conditions with indications for NSAID use, particularly arthritis, may be more bothersome and limiting to overall quality of life than coexisting CKD, which is often without symptoms before end-stage renal disease. Indeed, we found that current NSAID use was 2- to 5 -fold higher among those with arthritis compared with those without arthritis, regardless of CKD status. Thus, although primary care and general medicine textbooks ${ }^{2-4}$ and clinical practice guidelines ${ }^{5}$ recommend avoidance of NSAIDs for most CKD patients, clinicians are advised to consider the risks and benefits on a case-by-case basis, with determination and consideration of their patients' CKD status and over-the-counter NSAID use. For example, for a patient with pain caused by arthritis or other conditions, the potential risk of CKD progression resulting from NSAID use may be outweighed by improved patient quality of life. Such trade-offs must be considered.

\section{Study Limitations}

First, although we can show that high-risk use of NSAIDs is common among those with CKD, no causal inference can be drawn. Also, acute kidney injury cannot be distinguished from CKD in a crosssectional study. CKD status before the NHANES survey is unknown, so only current NSAID use can be examined in relation to CKD. Second, our main definition did not include the most commonly used over-the-counter analgesics-acetaminophen and aspirin-because of their relatively low nephrotoxicity and indications for pain and cardiovascular prevention, respectively. Even though prolonged, high-dose use of acetaminophen ${ }^{23,28}$ or aspirin may be nephrotoxic, however, they are recommended as analgesics in the setting of CKD. Third, participants with chronic pain may over- or underestimate the duration and frequency of NSAID use or may not recognize medi- cations as NSAIDs; reporting could also be biased by psychosocial reasons (eg, attention-seeking behavior or embarrassment). We did not have information on indication, clinician recommendation, or detailed dosage and frequency. Fourth, there is the possibility of CKD misclassification, particularly for earlier stages. Data from more recent NHANES (2005-2008) did not include information on NSAID use, somewhat limiting the generalizability of the results to current practices. Finally, information on comorbid conditions was selfreported and, likely, underreported.

In summary, reported current use of NSAIDs in the United States is low, but it is as common among those with CKD as in those without CKD, even among those who are aware of their CKD. Primary care physicians, who are likely to manage both earlystage CKD and indications for NSAID use, should be aware of the rates of NSAID (both prescribed and over-the-counter) use, assess the risk of NSAID use in each patient, and, most importantly, engage each patient in informed decision making about the risks and benefits of NSAID use. CKD screening in those who use NSAIDs daily and effective communication of the risks of NSAID use among those with CKD may be warranted to prevent further kidney damage and progression of disease.

To read or post commentaries in response to this article, see it online at http://www.annfammed.org/cgi/content/full/9/5/423.

Key words: Nonsteroidal anti-inflammatory agents; over-the-counter drugs; chronic kidney failure; medication errors

Funding support: This project was supported under a cooperative agreement from the Centers for Disease Control and Prevention (CDC) through the Association of American Medical Colleges (AAMC), grant number 5U36CD319276, AAMC identification number MM-1143-10/10. Dr. Powe is partially supported by the National Institute of Diabetes and Digestive and Kidney Diseases (grant K24DK02643).

Disclaimer: Publication and report contents are solely the responsibility of the authors and do not necessarily represent the official views of the AAMC or CDC.

This work was presented in part at the American Society of Nephrology annual meeting, November 18-21, 2010, in Denver, Colorado.

Acknowledgments: The CDC CKD Surveillance Team consists of members from University of California, San Francisco (Neil Powe, Laura Plantinga, Kirsten Bibbins-Domingo, Josef Coresh, Alan Go, Chi-yuan Hsu, Lesley Inker, Deidra Crews, Vanessa Grubb, Delphine Tuot, Seena Nair); University of Michigan, Ann Arbor (Rajiv Saran, Elizabeth Hedgeman, Brenda Gillespie, William Herman, Freidrich Port, Bruce Robinson, Vahakn Shahinian, Jerry Yee, Eric Young); and Centers for Disease Control and Prevention, Atlanta (Desmond Williams, Nilka Ríos Burrows, Mark Eberhardt, Paul Eggers, Nicole Flowers, Linda Geiss, Susan Hailpern, Regina Jordan, Juanita Mondesire, Bernice Moore, Gary Myers, Meda Pavkov, Deborah Rolka, Sharon Saydah, Anton Schoolwerth, Rodolfo Valdez, Larry Waller). 


\section{References}

1. Paulose-Ram R, Hirsch R, Dillon C, Losonczy K, Cooper M, Ostchega $Y$. Prescription and non-prescription analgesic use among the US adult population: results from the third National Health and Nutrition Examination Survey (NHANES III). Pharmacoepidemiol Drug Saf. 2003;12(4):315-326.

2. Goroll AH, Mulley AG Jr, eds. Primary Care Medicine: Office Evaluation and Management of the Adult Patient. 6th ed. Philadelphia, PA: Wolters Kluwer Health/Lippincott Williams \& Wilkins; 2009.

3. Barker LR, Zieve PD, eds. Principles of Ambulatory Medicine. 7th ed. Philadelphia, PA: Lippincott Williams \& Wilkins; 2007.

4. Fauci AS, ed. Harrison's Principles of Internal Medicine. 17th ed. New York, NY: McGraw-Hill Medical; 2008.

5. National Kidney Foundation. Kidney disease outcomes quality initiative (K/DOQI). http://www.kidney.org/professionals/doqi.

6. Plantinga LC, Boulware LE, Coresh J, et al. Patient awareness of chronic kidney disease: trends and predictors. Arch Intern Med. 2008;168(20):2268-2275.

7. Nayak-Rao S. Achieving effective pain relief in patients with chronic kidney disease: A review of analgesics in renal failure. J Nephrol. 2010; 24(1):5-40.

8. Huerta C, Castellsague J, Varas-Lorenzo C, García Rodríguez LA. Nonsteroidal anti-inflammatory drugs and risk of ARF in the general population. Am J Kidney Dis. 2005;45(3):531-539.

9. Gooch K, Culleton BF, Manns BJ, et al. NSAID use and progression of chronic kidney disease. Am J Med. 2007;120(3):280,e1-7.

10. Clive DM, Stoff JS. Renal syndromes associated with nonsteroidal antiinflammatory drugs. N Engl J Med. 1984;310(9):563-572.

11. Rossert J. Drug-induced acute interstitial nephritis. [nephrology forum]. Kidney Int. 2001;60(2):804-817.

12. Guo X, Nzerue C. How to prevent, recognize, and treat druginduced nephrotoxicity. Cleve Clin J Med. 2002;69(4):289-290, 293294, 296-297 passim.

13. Moser M, Setaro JF. Clinical practice. Resistant or difficult-to-control hypertension. N Engl J Med. 2006;355(4):385-392.

14. Setaro JF, Black HR. Refractory hypertension. N Engl J Med. 1992; 327(8):543-547.

15. De Broe ME, Elseviers MM. Over-the-counter analgesic use. J Am Soc Nephrol. 2009;20(10):2098-2103.

16. Centers for Disease Control and Prevention (CDC). National Center for Health Statistics (NCHS). National Health and Nutrition Examination Survey Data. Hyattsville, MD: US Department of Health and Human Services, Centers for Disease Control and Prevention, 1999-2004. http://www.cdc.gov/nchs/nhanes/nhanes_questionnaires.htm.

17. Selvin E, Manzi J, Stevens LA, et al. Calibration of serum creatinine in the National Health and Nutrition Examination Surveys (NHANES) 1988-1994, 1999-2004. Am J Kidney Dis. 2007;50(6):918-926.
18. Centers for Disease Control and Prevention (CDC). National Center for Health Statistics (NCHS). Analytic and Reporting Guidelines: The National Health and Nutrition Examination Survey (NHANES). Hyattsville, MD: US Department of Health and Human Services, Centers for Disease Control and Prevention, 2006. http://www.cdc.gov/nchs/ nhanes/nhanes2003-2004/analytical_guidelines.htm.

19. Levey AS, Coresh J, Greene T, et al; Chronic Kidney Disease Epidemiology Collaboration. Expressing the Modification of Diet in Renal Disease Study equation for estimating glomerular filtration rate with standardized serum creatinine values. Clin Chem. 2007;53(4):766-772.

20. Henrich WL, Agodoa LE, Barrett B, et al. Analgesics and the kidney: Summary and recommendations to the scientific advisory board of the National Kidney Foundation from an ad hoc committee of the National Kidney Foundation. Am J Kidney Dis. 1996;27(1): 162-165.

21. Levey AS, Stevens LA, Schmid CH, et al. CKD-EPI (Chronic Kidney Disease Epidemiology Collaboration). A new equation to estimate glomerular filtration rate. Ann Intern Med. 2009;150(9):604-612.

22. Sandler DP, Burr FR, Weinberg CR. Nonsteroidal anti-inflammatory drugs and the risk for chronic renal disease. Ann Intern Med. 1991; 115(3):165-172.

23. Perneger TV, Whelton PK, Klag MJ. Risk of kidney failure associated with the use of acetaminophen, aspirin, and nonsteroidal antiinflammatory drugs. N Engl J Med. 1994;331(25):1675-1679.

24. Murray MD, Brater DC, Tierney WM, Hui SL, McDonald CJ. Ibuprofen-associated renal impairment in a large general internal medicine practice. Am J Med Sci. 1990;299(4):222-229.

25. Gurwitz JH, Avorn J, Ross-Degnan D, Lipsitz LA. Nonsteroidal anti-inflammatory drug-associated azotemia in the very old. JAMA 1990;264(4):471-475.

26. Rexrode KM, Buring JE, Glynn RJ, Stampfer MJ, Youngman LD, Gaziano JM. Analgesic use and renal function in men. JAMA. 2001;286(3):315-321.

27. Kurth T, Glynn RJ, Walker AM, et al. Analgesic use and change in kidney function in apparently healthy men. Am J Kidney Dis. 2003; 42(2):234-244.

28. Curhan GC, Knight EL, Rosner B, Hankinson SE, Stampfer MJ. Lifetime nonnarcotic analgesic use and decline in renal function in women. Arch Intern Med. 2004;164(14):1519-1524.

29. Bennett WM, DeBroe ME. Analgesic nephropathy-a preventable renal disease. N Engl J Med. 1989;320(19):1269-1271.

30. Mihatsch MJ, Khanlari B, Brunner FP. Obituary to analgesic nephropathy-an autopsy study. Nephrol Dial Transplant. 2006; 21(11):3139-3145

31. Pintér I, Mátyus J, Czégány Z, et al. Analgesic nephropathy in Hungary: the HANS study. Nephrol Dial Transplant. 2004;19(4):840-843. 